\title{
(2) OPEN ACCESS \\ Prospective, randomized, multicenter study of intraosseous basivertebral nerve ablation for the treatment of chronic low back pain: 12-month results
}

\author{
Matthew Smuck, ${ }_{1}^{1}$ Jad Khalil, ${ }^{2}$ Kevin Barrette, ${ }_{1}^{3}$ Joshua Adam Hirsch, ${ }_{1}^{4}$ Scott Kreiner, \\ Theodore Koreckij, ${ }^{6}$ Steven Garfin, ${ }^{7}$ Nagy Mekhail, ${ }^{8}$ INTRACEPT Trial Investigators
}

\begin{abstract}
- Additional supplemental material is published online only. To view, please visit the journal online (http://dx.doi.org/ 10.1136/rapm-2020-102259).

${ }^{1}$ Physical Medicine \&

Rehabilitation Division, Stanford University, Redwood City,

California, USA

${ }^{2}$ Orthopaedic Surgery, William Beaumont Hospital, Royal Oak, Michigan, USA

${ }^{3}$ Neurological Surgery, University of California San Francisco, San Francisco, California, USA

${ }^{4}$ Department of

Neurointerventional Radiology, Massachusetts General Hospital, Boston, Massachusetts, USA

${ }^{5}$ Neurophysiatry, Barrow Neurological Institute, Phoenix, Arizona, USA

${ }^{6}$ Orthopaedic Surgery Spine, St Luke's Hospital, Kansas,

Missouri, USA

Orthopaedic Surgery, University of California San Diego, La Jolla, California, USA

${ }^{8}$ Anesthesiology, Cleveland Clinic, Cleveland, Ohio, USA
\end{abstract}

Correspondence to Dr Matthew Smuck, Physical Medicine \& Rehabilitation Division, Orthopaedic Surgery, Stanford University, Redwood City, CA 94305, USA: msmuck@stanford.edu

Received 2 November 2020

Accepted 26 April 2021 Published Online First 24 May 2021

Check for updates

(C) American Society of Regional Anesthesia \& Pain Medicine 2021. Re-use permitted under CC BY-NC. No commercial re-use. Published by BMJ.

To cite: Smuck M,

Khalil J, Barrette K, et al.

Reg Anesth Pain Med

2021:46:683-693.

\section{ABSTRACT}

Introduction Vertebral endplates, innervated by the basivertebral nerve (BVN), are a source of chronic low back pain correlated with Modic changes. A randomized trial comparing BVN ablation to standard care (SC) recently reported results of an interim analysis. Here, we report the results of the full randomized trial, including the 3-month and 6-month between-arm comparisons, 12-month treatment arm results, and 6-month outcomes of BVN ablation in the former SC arm.

Methods Prospective, open label, 1:1 randomized controlled trial of BVN ablation versus SC in 23 US sites with follow-up at 6 weeks, 3, 6, 9, and 12 months. SC patients were re-baselined and followed up for 6 months post BVN ablation. The primary endpoint was the between-arm comparison of mean Oswestry Disability Index (ODI) change from baseline. Secondary endpoints were Visual Analog Scale (VAS), Short Form (SF-36), EuroQual Group 5 Dimension 5-Level Quality of Life (EQ$5 \mathrm{D}-5 \mathrm{~L})$, responder rates, and rates of continued opioid use.

Results 140 were randomized. Results from BVN ablation ( $n=66)$ were superior to SC $(n=74)$ at 3 months for the primary endpoint (mean ODI reduction, difference between arms of $-20.3(\mathrm{Cl}-25.9$ to -14.7 points; $p<0.001)$ ), VAS pain improvement (difference of -2.5 $\mathrm{cm}$ between arms $(\mathrm{Cl}-3.37$ to $-1.64, \mathrm{p}<0.001))$ and quality of life outcomes. At 12 months, basivertebral ablation demonstrated a $25.7 \pm 18.5$ point reduction in mean ODI $(p<0.001)$, and a $3.8 \pm 2.7 \mathrm{~cm}$ VAS reduction $(p<0.001)$ from baseline, with $64 \%$ demonstrating $\geq 50 \%$ reduction and $29 \%$ pain free. Similarly, the former SC patients who elected BVN ablation (92\%) demonstrated a $25.9 \pm 15.5$ point mean ODI reduction $(p<0.001)$ from baseline. The proportion of opioid use did not change in either group $(p=0.56)$.

Discussion/Conclusion BVN ablation demonstrates significant improvements in pain and function over SC, with treatment results sustained through 12 months in patients with chronic low back pain of vertebrogenic origin.

\section{INTRODUCTION}

Clinicians who treat chronic low back pain (CLBP) are challenged by the varied and complex causes and by low effect sizes of treatments. ${ }^{1}$ They have long recognized that better subgrouping of patients is necessary for more targeted and effective treatments. One such subgroup is vertebrogenic CLBP.
While this diagnosis represents a newer clinical concept, there is a substantial body of basic science evidence indicating this as an important source of CLBP. ${ }^{2-5}$ Furthermore, an association has been established between the presence of type 1 or type 2 Modic changes and CLBP. ${ }^{67}$ Vertebral endplate nociceptors trace back to the basivertebral nerve $(\mathrm{BVN}){ }^{3}$ a potential target for therapeutic radiofrequency ablation of the BVN in the subgroup of patients with vertebrogenic CLBP.

A previous randomized, double-blind, shamcontrolled trial demonstrated the efficacy of BVN ablation to treat CLBP in this patient subgroup, with durability of benefits for 2 and 5 years. ${ }^{8-10}$ Based on these findings, a new randomized controlled trial (RCT) was designed to evaluate the clinical effectiveness of BVN ablation compared with standard care (SC) for CLBP in patients with Modic type 1 or 2 changes. The outcome from this study's interim analysis was recently published, based on an independent Data Management Committee (DMC) recommendation to halt enrollment and offer the SC arm BVN ablation after re-baseline due to statistical superiority of BVN ablation over SC. ${ }^{11}$ Here, we report the outcomes of the entire RCT cohort at the 3-month primary endpoint and at 6 months (point of randomization stop and re-baseline for the SC arm), the 12-month results of the entire BVN ablation arm, and the 6-month results from BVN ablation in the former SC arm.

\section{METHODS \\ Design}

The INTRACEPT trial is a prospective, parallel, open-label RCT of 420 patients recruited at 23 US sites, with 140 eligible patients randomized from September 2017 to January 2019. The trial was registered in August 2017 on ClinicalTrials. gov as NCT03246061 (https://clinicaltrials.gov/ct2/ show/NCT03246061) and sponsored by Relievant Medsystems (Minneapolis, Minnesota, USA). The study is Health Insurance Portability and Accountability Act (HIPAA) compliant and was conducted under Institutional Review Board approval and participant informed consent. Enrolled patients were assigned a unique deidentified ID number. Data were source-verified by independent study monitors. Third-party statisticians (Abond, Grand Rapids, Michigan, USA) prepared the computergenerated randomization scheme and conducted 
Table 1 Inclusion and exclusion criteria: Listing of the inclusion and exclusion criteria for the study are noted below

\begin{tabular}{|c|c|}
\hline Inclusion criteria & Exclusion criteria \\
\hline $\begin{array}{l}\text { Skeletally mature patients with chronic ( } \geq 6 \text { months) isolated lumbar back pain, } \\
\text { who had not responded to at least } 6 \text { months of non-operative management } \\
\text { Type } 1 \text { or type } 2 \text { Modic changes at one or more vertebral body for levels L3-S1 } \\
\text { Minimum Oswestry Disability Index (ODI) of } 30 \text { points ( } 100 \text {-point scale) } \\
\text { Minimum Visual Analog Scale (VAS) of } 4 \mathrm{~cm} \text { on a } 10 \mathrm{~cm} \text { scale } \\
\text { Ability to provide informed consent, read and complete questionnaires }\end{array}$ & $\begin{array}{l}\text { MRI evidence of Modic at levels other than lumbar level } 3 \text { to sacral level } 1 \text { (L3-S1) } \\
\text { Radicular pain (defined as nerve pain following a dermatomal distribution and that } \\
\text { correlates with nerve compression in imaging) } \\
\text { Previous lumbar spine surgery (discectomy/laminectomy allowed if }>6 \text { months prior to } \\
\text { baseline and radicular pain resolved) } \\
\text { Symptomatic spinal stenosis (defined as the presence of neurogenic claudication and } \\
\text { confirmed by imaging) } \\
\text { Metabolic bone disease, spine fragility fracture history, or trauma/compression } \\
\text { fracture, or spinal cancer } \\
\text { Spine infection, active systemic infection, bleeding diathesis } \\
\text { Radiographic evidence of other pain etiology } \\
\text { Disc extrusion or protrusion }>5 \text { mm } \\
\text { Spondylolisthesis }>2 \text { mm at any level } \\
\text { Spondylolysis at any level } \\
\text { Facet arthrosis/effusion correlated with clinically suspected facet-mediated low back } \\
\text { pain } \\
\text { Beck Depression Inventory (BDI) }>24 \text { or } 3 \text { or }>\text { Waddell's signs } \\
\text { Compensated injury or litigation } \\
\text { Currently taking extended-release narcotics with addiction behaviors } \\
\text { Body mass index (BMI) }>40 \\
\text { Bedbound or neurological condition that prevents early mobility or any medical } \\
\text { condition that impairs follow-up } \\
\text { Contraindication to MRI, allergies to components of the device, or active implantable } \\
\text { devices, pregnant or lactating }\end{array}$ \\
\hline
\end{tabular}

BDI, Beck Depression Index; BMI, body mass index; ODI, Oswestry Disability Index; VAS, Visual Analog Scale.

the statistical analyses. Full design details were previously published. $^{11}$

\section{Participants}

Participants were drawn from clinics and online advertising with additional telephonic screening by independent research associates. Consecutively identified patients were consented and screened for eligibility by investigative sites prior to conducting MRI review for endplate changes and radiographic exclusion criteria. Prior to randomization, final eligibility was adjudicated by an independent orthopedic surgeon medical monitor based on clinical and radiographic presentation. The primary requirements for inclusion were CLBP duration of greater than 6 months with conservative treatment and Modic type 1 or type 2 changes from L3 to S1. See table 1 for a full listing of the inclusion and exclusion criteria. Consecutive eligible patients were randomized 1:1 to either BVN ablation plus continued SC or SC alone using permuted blocks of four or six stratified by study site.

\section{Interventions}

Patients randomized to BVN ablation received treatment at each level that exhibited qualifying Modic changes using the Intracept System (Relievant Medsystems, Minneapolis, Minnesota, USA) as previously described. ${ }^{8}{ }^{11} \mathrm{SC}$ was provided to both treatment arms in a shared decision-making process between the patient and the treating investigator, including but not limited to the following: physical therapy, exercise, chiropractic treatment, acupuncture, oral pain medications and spinal injections.

\section{Follow-Up}

The primary endpoint of the study was collected at 3 months post randomization (SC arm) or 3 months post-treatment (BVN ablation arm). Per the original protocol design, BVN ablation patients are followed at 6 weeks, and 3, 6, 9, 12, and 24 months. SC arm patients were to be followed up at $3,6,9$, and 12 months, and then offered BVN ablation. With statistical superiority demonstrated in the primary and secondary endpoints at the interim analysis, and per informed consent and protection of human subjects' requirements for disclosure of new findings that may impact a research participant's willingness to continue in a study, the DMC recommended that SC arm patients be re-baselined at their next scheduled visit, informed of the new findings, and allowed early treatment with BVN ablation. Re-baseline occurred at a median of 175 (range 24-372) days post randomization. SC arm patients who elected BVN ablation were followed at 6 weeks, 3 months, and 6 months post-treatment, then exited from the study. SC patients that declined BVN ablation were exited from the study.

\section{Target success}

MRI (T1, T2, and short tau inversion recovery (STIR) time constants) was performed at 6 weeks post BVN ablation for all treated patients. Measurements of the degree of overlap between the radiofrequency ablation lesion and the terminus of the BVN for each vertebral body with Modic changes were performed by an independent, blinded neuroradiologist reviewer, with target success based on a predefined threshold of overlap. All levels with either type 1 or type 2 Modic changes between L3 and S1 were required to be treated. Baseline and 6-week MRIs were paired for Modic changes and treated levels. Untreated levels with Modic changes were deemed a target failure.

\section{Outcome measures}

Validated patient-reported outcomes were completed by subjects at each study visit including functional impact using the Oswestry Disability Index $(\mathrm{ODI})^{12}$ with a minimal clinically important difference (MCID) of 15 points, ${ }^{13}$ low back pain using a Visual Analog Scale (VAS) ${ }^{14}$ from 0 (no pain) to 10 (worst pain imaginable) with an MCID of $2.0 \mathrm{~cm},{ }^{13}$ and health status and quality of life (QOL) using the Short Form $(\mathrm{SF}-36)^{15}$ with a physical component MCID of $4.9^{13}$ and EuroQual Group 5 Dimension 
5-Level Quality of Life (EQ-5D-5L) 16 $^{16}$ with an MCID of 0.03 point. ${ }^{13}$ All were collected by the site's research coordinator who transferred them into an electronic data collection system, and all electronic entries were verified as accurate to the source patient questionnaires by third-party monitors. Spinal and neurological adverse events (AEs) were collected at each study visit and were adjudicated by an independent clinical event committee and determination of relatedness to the device therapy was made.

\section{Sample calculations}

The primary outcome of this study is change in ODI at 3 months. The study had a group-sequential design with one planned interim analysis for primary end-point superiority testing after $60 \%$ of randomized patients completed their 3-month follow-up. The study was $80 \%$ powered to detect a 10 -point difference in ODI with a two-sided overall alpha level of 0.05 . Initial sample size was 150 patients (75 in each group) with an estimated 15\% attrition rate. The interim analysis resulted in early termination of enrollment as described. ${ }^{11}$

\section{Statistical analysis}

Outcomes were analyzed as intent to treat (ITT). Statistical analysis was performed with SAS V.9.3 software (SAS Institute), using an analysis of covariance (ANCOVA) with a factor of treatment group and a covariate of baseline ODI score for the primary endpoint, producing least squares (LS) means for statistical comparison. Adjustment for ODI and VAS baseline scores was made due to known ceiling and floor effects for these measurements. ${ }^{12} 17$ Missing values for the 3-month primary endpoint were imputed using multiple imputations. Statistical significance of the primary endpoint was defined as $\mathrm{p}<0.025$ for the group sequential design for an overall alpha of $\mathrm{p}<0.05$. Six-month results were reported as last visit prior to the SC arm being offered BVN ablation. Secondary endpoints of VAS, SF-36, and EQ-5D-5L were similarly analyzed using an ANCOVA for between-arm comparisons. Responder rates using MCID thresholds described above were analyzed using Fisher's exact test. A paired t-test of significance was performed for 12 -month endpoints of ODI and VAS change from baseline in the BVN ablation arm, and 3 and 6 months after BVN ablation in the former SC arm.

\section{Study revisions}

Protocol revisions allowed for treatment of up to four vertebrae and non-consecutive levels from L3-S1 with Food and Drug Administration (FDA) clearance, as described previously ${ }^{11}$ and the addition of an optional 5-year follow-up substudy for treatment arm patients. An evaluation of the impact of protocol revisions to the primary endpoint detected no significant differences, so no adjustment was required. A final study revision stopped enrollments and randomization and allowed for early re-baseline and offering of BVN ablation to the $\mathrm{SC}$ arm patients per the DMC recommendation.

\section{RESULTS}

Patient

At the time of the DMC recommendation to stop enrollment, 140 patients were randomized (66 BVN ablation, 74 SC) at 20 out of 23 study sites. The percentage of patients with LBP symptoms $\geq 5$ years was $71.4 \%$. Overall, baseline ODI was 45.9 ; VAS was 6.8; and mean age was 49.7 years. Demographics and baseline characteristics of the two randomized populations were similar (see table 2).

In the SC arm, seven patients withdrew or were lost to follow-up, and one patient exited for disc herniation surgery. Of the remaining 66 SC patients, 61 (92\%) elected to receive BVN ablation and 5 declined ablation treatment (see figure 1).

Table 2 Baseline characteristics

\begin{tabular}{|c|c|c|c|c|c|}
\hline & $\begin{array}{l}\text { All randomized } \\
(\mathrm{N}=140)\end{array}$ & $\begin{array}{l}\text { Basivertebral nerve } \\
\text { ablation arm } \\
(\mathrm{N}=66)\end{array}$ & $\begin{array}{l}\text { Standard care arm } \\
(\mathrm{N}=74)\end{array}$ & $\begin{array}{l}\text { BVN ablation in former } \\
\text { standard care arm } \\
(\mathrm{N}=61)\end{array}$ & $P$ value \\
\hline Mean age in years (range) & $49.7(26-70)$ & $49.4(30-68)$ & $50.0(26-70)$ & $49.5(26-70)$ & $0.73^{*}$ \\
\hline Male, n (\%) & $71(50.7 \%)$ & $34(51.5 \%)$ & $37(50.0 \%)$ & $31(50.8 \%)$ & $0.87 \dagger$ \\
\hline Duration LBP symptoms $\geq 5$ years, $n(\%)$ & $100(71.4 \%)$ & $42(63.6 \%)$ & $58(78.4 \%)$ & $49(80.3 \%)$ & $0.06+$ \\
\hline Mean days per week with LBP & $6.9(4-7)$ & $6.8(4-7)$ & $6.9(4-7)$ & $6.9(4-7)$ & $0.98^{*}$ \\
\hline Mean ODI (range) & $45.9(30-88)$ & $44.7(30-76)$ & $46.9(30-88)$ & $46.2(26-76)$ & $0.30^{*}$ \\
\hline Mean VAS (range) & $6.79(4.0-10.0)$ & $6.73(4.0-10.0)$ & $6.85(4.0-10.0)$ & $6.78(3.0-100)$ & $0.61^{*}$ \\
\hline Mean SF-36 PCS ${ }^{2}$ (range) & $32.1(17.2-47.6)$ & $32.1(18.4-46.9)$ & $32.1(17.2-47.6)$ & $33.1(20.9-45.2)$ & $0.95^{*}$ \\
\hline Mean SF-36 MCS (range) & $52.9(22.2-69.8)$ & $53.4(22.2-69.8)$ & $52.4(29.4-69.4)$ & $49.2(21.6-66.3)$ & $0.54^{*}$ \\
\hline Mean EQ-5D-5L (range) & $0.61(.25-.83)$ & $0.61(.27-.83)$ & $0.61(.25-.83)$ & $0.61(.28-.86)$ & $0.89^{*}$ \\
\hline Mean $\mathrm{BDI}^{5}$ (range) & $6.3(0-20)$ & $6.2(0-20)$ & $6.4(0-20)$ & $6.7(0-20)$ & $0.89^{*}$ \\
\hline \multicolumn{6}{|l|}{ Treatment history, n (\%) } \\
\hline Opioid use at baseline & $40(28.6 \%)$ & $22(33.3 \%)$ & $18(24.3 \%)$ & $14(23.0 \%)$ & $0.27 \dagger$ \\
\hline Injections & $95(67.9 \%)$ & $42(63.6 \%)$ & $53(71.6 \%)$ & $44(72.1 \%)$ & $0.37 \dagger$ \\
\hline Past lower back surgeries & $14(10.0 \%)$ & $7(10.6 \%)$ & $7(9.5 \%)$ & $5(8.2 \%)$ & $1.00 t$ \\
\hline Type of Modic by subject, n (\%) & & & & & $0.86 \ddagger$ \\
\hline Type 1 & $52(37.1 \%)$ & $23(34.8 \%)$ & $29(39.2 \%)$ & $26(42.6 \%)$ & \\
\hline Type 2 & $70(50.0 \%)$ & $34(51.5 \%)$ & $36(48.6 \%)$ & $29(47.5 \%)$ & \\
\hline Mixed (type 1 and type 2) & $18(12.9 \%)$ & $9(13.6 \%)$ & $9(12.2 \%)$ & $6(9.8 \%)$ & \\
\hline
\end{tabular}

Demographic and baseline characteristics for randomized patients demonstrated no statistically significant differences between arms.

${ }^{*} P$ value from a two-sample $t$-test with a factor of treatment group.

tP value from a Fisher's exact test with a factor of treatment group.

$\ddagger P$ value from a $\chi^{2}$ test with a factor of treatment group.

BDI, Beck Depression Index; BVN, basivertebral nerve; BVNA, basivertebral nerve ablation; EQ-5D-5L, EuroQual Group 5 Dimension 5-Level Quality of Life; LBP, low back pain; MCS, Mental Component Summary; ODI, Oswestry Disability Index; PCS, Physical Component Summary; SF-36, Short Form 36; VAS, Visual Analog Scale. 


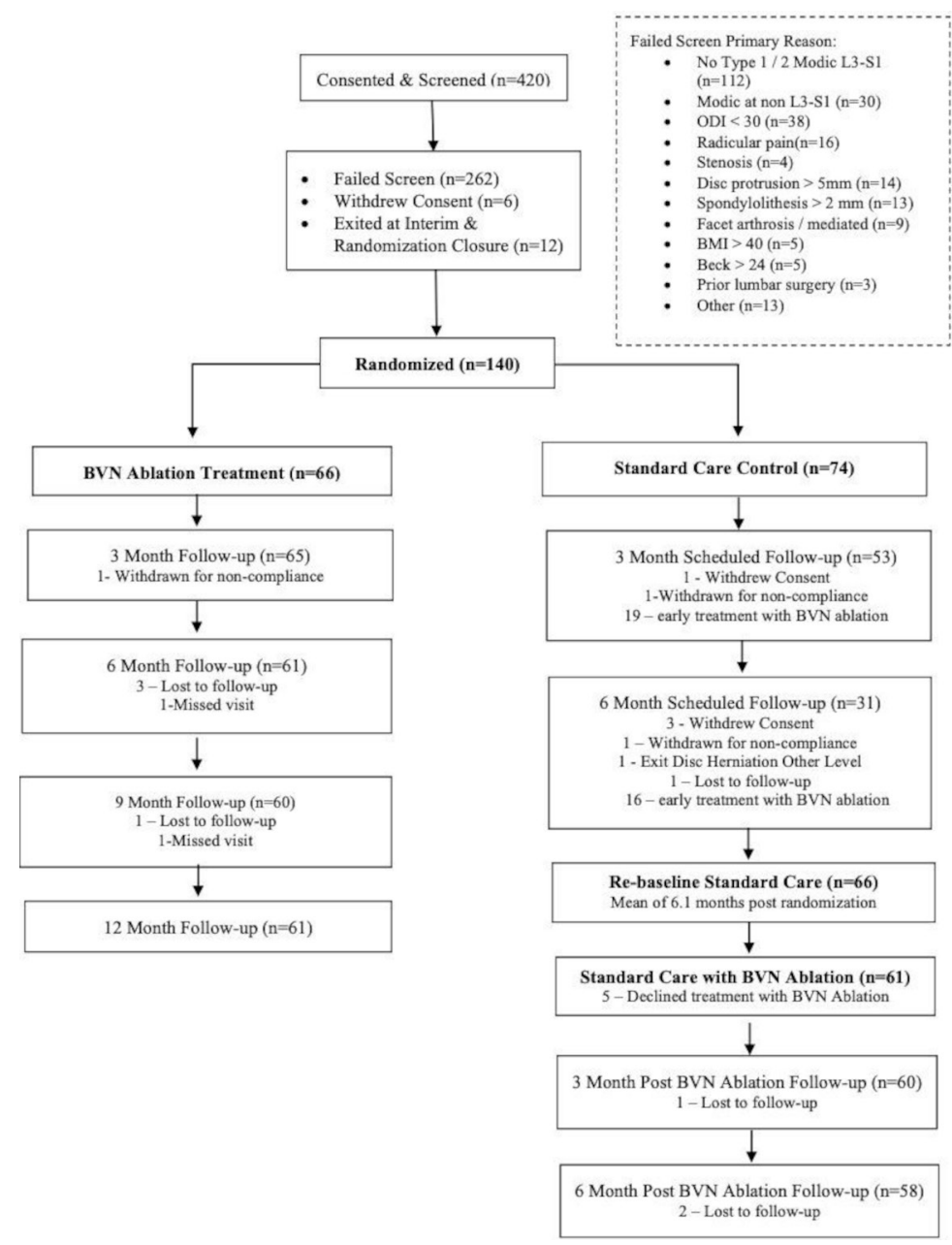

Figure 1 Consort flow diagram. One hundred forty patients were randomized to BVN ablation or standard care. After the study was halted due to statistical superiority at interim analysis, standard care arm patients $(n=66)$ were offered BVN ablation, with 61 electing to receive BVN ablation, 3 of whom were lost to follow-up. BMI, body mass index; BVN, basivertebral nerve; ODI, Oswestry Disability Index; VAS, Visual Analog Scale.

\section{Treatment results}

In the BVN ablation arm, two vertebral bodies were treated in 51 patients $(77.3 \%)$, three vertebral bodies in 14 patients $(21.2 \%)$, and four vertebral bodies in 1 patient $(1.5 \%)$. The most often treated vertebral body was L5 (98.5\%), followed by S1 (62.1\%), and L4 (54.5\%). Mean procedure duration was $88.0 \mathrm{~min}$ (SD 37.1) from incision to closure. Targeting was adjudicated as successful in $97 \%$ of patients and in $99 \%$ of vertebral bodies. Similar targeting success was demonstrated following BVN ablation in the former SC arm with evaluable MRIs (93\% of patients and $96 \%$ of vertebral bodies), with two subjects treated at L5/ S1, who did not have a 6-week MRI to evaluate conservatively deemed a target failure. Patients with one or more levels of targeting failure are included in this ITT analysis.

\section{3-Month $\mathrm{RCT}$ results}

The primary endpoint was a between-arm comparison of change in LS mean ODI scores at 3 months, adjusted for baseline ODI. The BVN ablation arm demonstrated -24.3 point LS mean improvement in ODI compared with -4.0 points for the $S C$ arm, a difference of -20.3 (CI -25.9 to -14.7 points; $p<0.001)$. ODI responder rates differed significantly $(\mathrm{p}<0.001)$ between $\mathrm{BVN}$ ablation and SC arms at the 15-point MCID (69.2\% vs 20.8\%) and at a 20 -point threshold (61.5\% vs $13.2 \%)$ (see table 3 ).
Secondary outcomes also demonstrated statistically significant and clinically meaningful (above established MCID) benefits in favor of BVN ablation over SC. BVN ablation patients reported an LS mean change in VAS of $-3.5 \mathrm{~cm}$ versus $-1.0 \mathrm{~cm}$ for SC, a difference of $-2.5 \mathrm{~cm}(\mathrm{CI}-3.4$ to $-1.6 ; \mathrm{p}<0.001)$. Quality of life differences were nearly six times the MCID for EQ-5D-5L and twice the MCID for the SF-36 physical component in favor of BVN ablation. See table 4 for VAS results and table 5 for QOL results. Unadjusted ODI and VAS improvements were also statistically significant and are presented in online supplemental table 1 .

\section{6-Month RCT results}

The 6-month results of the BVN ablation arm are compared with the last attended visit prior to re-baseline and offering BVN ablation treatment to the SC arm (median of 176.5 days). There were statistically significant and clinically meaningful differences in all patient-reported outcomes. The LS mean change in ODI was -26.1 for BVN ablation compared with -1.6 for SC; a -24.5 difference (CI -29.4 to -19.6 ; $\mathrm{p}<0.001$ ) (see table 3 ). Back pain LS mean improvements in VAS were $-3.6 \mathrm{~cm}$ vs $-0.3 \mathrm{~cm}$ for BVN ablation and SC, respectively: a -3.3 difference (CI -4.0 to $-2.6 ; \mathrm{p}<0.001$ ) (see table 4 ). ODI responder rates (at MCID of 15 points) were $67.2 \%$ in the BVN ablation arm vs $12.5 \%$ in the SC arm $(\mathrm{p}<0.001)$. A combined MCID responder rate for 
Original research

Table 3 Oswestry Disability Index (ODI) between arm results

\begin{tabular}{|c|c|c|c|c|}
\hline Oswestry disability index (ODI) & Basivertebral nerve ablation arm $(\mathrm{N}=66)$ & Standard care arm $(\mathrm{N}=74)$ & LS mean difference between arms & $P$ value \\
\hline Baseline ODI Mean, SD (Range) & $44.7,11.3(30-76)$ & $46.9,11.7$ (30 to 88 ) & & $0.30^{*}$ \\
\hline 3-Month ODI & $\mathrm{n}=66 \mathrm{~b} \dagger$ & $\mathrm{n}=74 \uparrow$ & & \\
\hline Mean, SD (Range) & $21.0,15.9(0-62)$ & $42.3,15.8(7-75)$ & & \\
\hline Mean change from baseline, SD & $-23.7,18.0$ & $-4.6,15.0$ & & \\
\hline LS Mean change $(95 \% \mathrm{Cl})$ & $-24.3,(-28.0$ to -20.7$)$ & $-4.0,(-8.2$ to 0.1$)$ & $-20.3,(-25.9$ to -14.7$)$ & $<0.001 \ddagger$ \\
\hline 6-Month ODI & $\mathrm{n}=61 \S$ & $\mathrm{n}=729$ & & \\
\hline Mean, SD (Range) & $19.1,15.4(0-56)$ & $44.8,14.3(6-76)$ & & \\
\hline Mean change from baseline, SD & $-25.1,17.4$ & $-2.4,14.3$ & & \\
\hline LS Mean change $(95 \% \mathrm{Cl})$ & $-26.1(-29.7$ to -22.5$)$ & $-1.6(-4.9$ to 1.7$)$ & $-24.5(-29.4$ to -19.6$)$ & $<0.0001 \mathrm{c}$ \\
\hline 3 Month ODI Responder Rates & $\mathrm{n}=65 \S$ & $n=539$ & & \\
\hline$\geq 15$-point reduction $n(\%)$ & $45(69.2 \%)$ & $11(20.8 \%)$ & & $<0.001 \mathrm{f}$ \\
\hline$\geq 20$-point reduction $\mathrm{n}(\%)$ & $40(61.5 \%)$ & $7(13.2 \%)$ & & $<0.001^{* *}$ \\
\hline 6 Month ODI Responder Rates & $n=61 \S$ & $n=619$ & & \\
\hline$\geq 15$-point reduction n(\%) & $41(67.2 \%)$ & $9(12.5 \%)$ & & $<0.001^{* *}$ \\
\hline$\geq 20$-point reduction $\mathrm{n}(\%)$ & $38(62.3 \%)$ & $8(11.1 \%)$ & & $<0.001^{* *}$ \\
\hline
\end{tabular}

The primary outcome measure for this study is the difference in least squares (LS) mean change in ODI between the basivertebral nerve (BVN) ablation arm and the standard care arm at 3 months of follow-up. Significant differences in LS mean reduction in ODI and responder rates were observed at both 3 and 6 months between the arms.

${ }^{*} P$ value from a two-sample t-test with a factor of treatment group. Testing between randomized arms.

tMultiple imputations were used to impute missing values for 3-month primary endpoint change in ODI.

¥Estimates and $p$ value from an ANCOVA with a factor of treatment group and a covariate of baseline ODI score. Values have been adjusted for multiple imputations.

$\S$ As observed. No imputations for missing values.

ПS

**P value from a Fisher's exact test.

ANCOVA, analysis of covariance; LS, least squares; ODI, Oswestry Disability Index.;

pain and function ( $\geq 2$-point VAS and $\mathrm{a} \geq 15$-point ODI) favored BVN ablation to SC $(58.3 \%$ vs $6.0 \%, \mathrm{p}<0.001)$ (see table 6$)$. There was no change in the proportion of chronic opioid use in either treatment arm $(6.6 \%$ vs $3.0 \%, \mathrm{p}=0.56)$.

\section{BVN ablation arm: 12-month results}

Improvements in pain and function in the BVN ablation arm were maintained for all patient-reported outcomes at 12 months. There was a statistically significant and clinically meaningful reduction in mean ODI $(-25.7 \pm 18.5$ points, $\mathrm{p}<0.001)$ and mean VAS
$(-3.8 \pm 2.6 \mathrm{~cm}, \mathrm{p}<0.001)$ at 12 months post ablation (see table 7$)$. Sixty-four per cent of the BVN ablation arm patients reported a $\geq 50 \%$ reduction in VAS, $44.3 \%$ achieved a $>75 \%$ reduction and $29.5 \%$ reported $100 \%$ pain relief at 12 months (see figure 2).

An ODI improvement of $\geq 15$ points was reported in $68.9 \%$ and $\geq 20$ points in $60.7 \%$. The combined MCID function and pain responder rate was $65.6 \%$ (see table 6). Quality of life outcomes measured via SF-36 (physical component) and EQ-5D-5L remained significantly improved from baseline (see table 8).

\begin{tabular}{|c|c|c|c|c|}
\hline Visual Analog Scale (VAS) & $\begin{array}{l}\text { Basivertebral nerve } \\
\text { ablation arm }(\mathrm{N}=66)\end{array}$ & $\begin{array}{l}\text { Standard care } \\
\operatorname{arm}(\mathrm{N}=74)\end{array}$ & $\begin{array}{l}\text { LS mean difference } \\
\text { between arms }\end{array}$ & $P$ value \\
\hline \multicolumn{5}{|l|}{ Baseline VAS } \\
\hline Mean, SD (range) & $6.7,1.3(4-10)$ & $6.9,1.3(4-10)$ & & $0.61^{*}$ \\
\hline 3-Month VAS & $\mathrm{n}=66+$ & $n=51+$ & & \\
\hline Mean, SD (rRange) & $3.2,2.7$ (0 to -10$)$ & $5.8,2.2$ (0 to -10$)$ & & \\
\hline Mean change from baseline, SD & $-3.5,2.6$ & $-1.1,2.1$ & & \\
\hline LS mMean change $(95 \% \mathrm{Cl})$ & $-3.5(-4.1$, to -3.0$)$ & $-1.0(-1.7$, to -0.4$)$ & $-2.5(-3.4$, to -1.6$)$ & $<0.001 \ddagger$ \\
\hline 6-Month VAS & $\mathrm{n}=60 t$ & $\mathrm{n}=70 \S$ & & \\
\hline Mean, SD (Rrange) & $3.1,2.4$ (0 to -8$)$ & $6.5,1.8(1$ to -10$)$ & & \\
\hline Mean change from baseline, SD & $-3.5,2.5$ & $-0.4,1.9$ & & \\
\hline LS Mmean change $(95 \% \mathrm{Cl})$ & $-3.6(-4.1$, to -3.1$)$ & $-0.3(-0.8$, to 0.2$)$ & $-3.3(-4.0$, to -2.6$)$ & $<0.001 \mp$ \\
\hline 3-Month VAS responder rates & $n=66 t$ & $\mathrm{n}=51+$ & & \\
\hline$\geq 2 \mathrm{~cm}$ reduction, $\mathrm{n}(\%)$ & $48(72.7 \%)$ & $17(33.3 \%)$ & & $<0.0019$ \\
\hline 6-Month VAS responder rates & $\mathrm{n}=60 t$ & $\mathrm{n}=70 \S$ & & \\
\hline$\geq 2$ cm reduction, $\mathrm{n}(\%)$ & $45(75.0 \%)$ & $12(17.1 \%)$ & & $<0.0019$ \\
\hline
\end{tabular}

Secondary outcome measures for this study included the difference in least squares (LS) mean change in VAS between the basivertebral nerve (BVN) ablation arm and the standard care arm. Significant differences in LS mean VAS reductions and responder rates (using a minimal clinically important difference of $\geq 2 \mathrm{~cm}$ reduction) were observed at both 3 and 6 months.

${ }^{*} \mathrm{P}$ value from a two-sample t-test with a factor of treatment group. Testing between randomized arms.

tAs observed, with no imputation for missing data.

¥Estimates and $p$ value from an ANCOVA with a factor of treatment group and a covariate of baseline VAS score.

$\S$ Standard care control arm 6-month last attended visit (median of 176.5 days). No imputations for missing data.

IP value from a Fisher's exact test.

LS, least squares; VAS, Visual Analog Scale. 
Original research

\begin{tabular}{|c|c|c|c|c|}
\hline Quality of life measurements & Basivertebral nerve ablation arm $(n=66)$ & Standard CareArm $(n=74)$ & LS mean difference between arms & P-Value \\
\hline Baseline SF-36 (PCS) & $n=66$ & $\mathrm{n}=74$ & & \\
\hline Mean, SD (Range) & $32.1,6.8(18.4-46.9)$ & $32.1,7.4(17.2-47.6)$ & & $0.95^{*}$ \\
\hline 3 Month SF-36 (PCS) & $\mathrm{N}=64 \dagger$ & $\mathrm{N}=51 \dagger$ & & \\
\hline Mean, SD (Range) & $45.6,9.7(22.3-60.8)$ & $33.6,7.2(14.9-50.8)$ & & \\
\hline Mean change from baseline, SD & $13.5,9.0$ & $2.2,6.2$ & & \\
\hline LS Mean change $(95 \% \mathrm{Cl})$ & $13.6(11.8$ to 15.5$)$ & $2.1(0.0$ to 4.1$)$ & 11.6 (8.8 to 14.4$)$ & $<0.001 \neq$ \\
\hline 6 Month SF-36 (PCS) & $\mathrm{n}=61 \dagger$ & $\mathrm{n}=70 \S$ & & \\
\hline Mean, SD (Range) & $45.8,9.7(26.4-59.9)$ & $33.9,7.1(20.9-54.9)$ & & \\
\hline Mean change from baseline, SD & $13.3,9.8$ & $1.9,7.1$ & & \\
\hline LS Mean change $(95 \% \mathrm{Cl})$ & $13.4(11.5,15.4)$ & $1.8(0.0,3.6)$ & $11.7(9.0,14.3)$ & $<0.001 \ddagger$ \\
\hline Baseline SF-36 (MCS) & $n=66$ & $\mathrm{n}=74$ & & \\
\hline Mean, SD (Range) & $53.4,9.5(22.2-69.8)$ & $52.4,9.4(29.4-69.4)$ & & $0.54^{*}$ \\
\hline 3 Month SF-36 (MCS) & $\mathrm{N}=64 t$ & $N=51 \dagger$ & & \\
\hline Mean, SD (Range) & $56.2,7.3$ (31.9 to 67.6$)$ & $50.3,11.4$ (17.6 to 66.2$)$ & & \\
\hline Mean change from baseline, SD & $2.3,6.8$ & $-2.4,9.6$ & & \\
\hline LS Mean change $(95 \% \mathrm{Cl})$ & 2.5 (0.7 to 4.4$)$ & $-2.7(-4.7$ to -0.6$)$ & $5.2(2.4$ to 8.0$)$ & $<0.001 \ddagger$ \\
\hline 6 Month SF-36 (MCS) & $\mathrm{N}=61 \dagger$ & $\mathrm{N}=70 \S$ & & \\
\hline Mean, SD (Range) & $55.1,8.4(23.3-69.8)$ & $49.0,11.6(21.6-66.3)$ & & \\
\hline Mean change from baseline, SD & $1.4,9.5$ & $-3.7,9.4$ & & \\
\hline LS Mean change $(95 \% \mathrm{Cl})$ & $1.6(-0.7$ to 3.8$)$ & $-3.9(-6.0$ to -1.8$)$ & 5.5 (2.4 to 8.5$)$ & $<0.001 \ddagger$ \\
\hline Baseline EQ-5D-5L & $n=66$ & $\mathrm{n}=74$ & & \\
\hline Mean, SD (Range) & $0.61,0.13(0.27-0.83)$ & $0.61,0.13(0.25-0.83)$ & & $0.89^{*}$ \\
\hline 3 Month EQ-5D-5L & $\mathrm{N}=65 t$ & $\mathrm{~N}=51 \dagger$ & & \\
\hline Mean, SD (Range) & $0.79,0.13(0.46-1.00)$ & $0.63,0.13(0.35-0.83)$ & & \\
\hline Mean change from baseline, SD & $0.18,0.15$ & $0.02,0.13$ & & \\
\hline LS Mean change $(95 \% \mathrm{Cl})$ & 0.18 (0.15 to 0.21$)$ & $0.02(-0.02$ to 0.05$)$ & $0.16,(0.12$ to 0.21$)$ & $<0.001 \neq$ \\
\hline 6 Month EQ-5D-5L & $\mathrm{N}=61 \dagger$ & $\mathrm{N}=70 \S$ & & \\
\hline Mean, SD (Range) & $0.81,0.14(0.50-1.00)$ & $0.61,0.14(0.28-0.86)$ & & \\
\hline Mean change from baseline, SD & 0.190 .16 & $-0.00,0.13$ & & \\
\hline LS Mean change $(95 \% \mathrm{Cl})$ & 0.19 (0.16 to 0.22 ) & $-0.01(-0.04$ to 0.02$)$ & $0.20,(0.15$ to 0.24$)$ & $<0.001 \ddagger$ \\
\hline
\end{tabular}

Secondary outcome measures for this study included the difference in LS mean change in quality of life (QOL) measures of Short Form-36 (physical and mental component summaries) and the EuroQual Group 5 Dimension 5-Level Quality of Life (EQ-5D-5L) between the basivertebral nerve (BVN) ablation arm and the standard care arm. Significant differences were observed in all QOL measurements between the study arms at 3 and 6 months.

${ }^{*} P$ value from a two-sample $t$-test with a factor of treatment group. Testing between randomized arms.

†As observed, with no imputation for missing data.

¥Estimates and $p$ value from an ANCOVA with a factor of treatment group and a covariate of baseline score.

$\S$ Standard care control arm 6 months as last attended (median follow-up of 176.5 days).

EQ-5D-5L, EuroQual Group 5 Dimension 5-Level Quality of Life; LS, least squares; MCS, Mental Component Summary; PCS, Physical Component Summary; QOL, quality of life; SF, Short Form.

\section{BVN ablation in the former SC arm: 6-month results}

BVN ablation in the former SC arm resulted in statistically significant (at $\mathrm{p}<0.001)$ and clinically meaningful improvements in pain and function at 3 and 6 months post BVN ablation from re-baseline. These patients demonstrated a $-24.7 \pm 18.5$-point change in mean ODI at 3 months and a $-25.9 \pm 17.1$-point change in mean ODI at 6 months (see table 9). Improvements in pain were also significant at 3 and 6 months, with a mean VAS reduction of $-3.5 \pm 2.6 \mathrm{~cm}$ at 3 months and a mean VAS reduction of $-3.8 \pm 2.9 \mathrm{~cm}$ at 6 months. Sixty-five per cent of these patients reported a $\geq 50 \%$ reduction in VAS, $36.2 \%$ achieved a $>75 \%$ reduction, and $22.4 \%$ reported $100 \%$ pain relief at 6 months post ablation treatment (see figure 3 ).

Comparable mean ODI and mean VAS reductions were demonstrated from BVN ablation in the former SC arm to those results observed at 3 and 6 months for the original treatment group (see figures 4 and 5). Health-related QOL measures were also significantly improved from re-baseline following BVN ablation in the former SC arm patients (see table 10).

\section{Additional treatments}

Within the 12 months prior to enrollment, $54.5 \%$ of BVN ablation arm patients received an epidural steroid injection (ESI). In the 12 months after BVN ablation, only 4.5\% (3/66) received an ESI involving the same region, compared with $18.0 \%(11 / 61)$ in the SC arm (mean=6.1 months). Following BVN ablation in the former SC arm, no patients had an ESI during the 6-month follow-up.

\section{Patient satisfaction}

Seventy-four per cent (74\%) of BVN ablation arm patients reported improvement of their condition at 12 months, with $75 \%$ indicating treatment success. Similar satisfaction $(78 \%$ improvement, $72 \%$ success) was reported 6 months after BVN ablation in the former SC arm.

\section{Adverse events}

No serious device-related AEs were reported. Four patients (3\%) complained of postoperative pain that was deemed related 
Table 6 Composite responder rates

\begin{tabular}{|c|c|c|c|}
\hline $\begin{array}{l}\text { Composite responder rates } \\
\text { ( } \geq 15 \text {-point ODI and } \geq 2 \mathrm{~cm} \\
\text { VAS reduction) }\end{array}$ & $\begin{array}{l}\text { Basivertebral } \\
\text { nerve ablation } \\
\text { arm } \\
(\mathrm{N}=66)\end{array}$ & $\begin{array}{l}\text { Standard care } \\
\text { arm } \\
(\mathrm{N}=74)\end{array}$ & $P$ value \\
\hline $\begin{array}{l}\text { 3-Month composite responders, } \\
\text { n (\%) }\end{array}$ & $\begin{array}{l}n=65^{*} \\
41(63.1 \%)\end{array}$ & $\begin{array}{l}n=51^{*} \\
7(13.7 \%)\end{array}$ & $<0.001 \dagger$ \\
\hline $\begin{array}{l}\text { 6-Month composite responders, } \\
\text { n (\%) }\end{array}$ & $\begin{array}{l}n=60^{*} \\
35(58.3 \%)\end{array}$ & $\begin{array}{l}n=67 \ddagger \\
4(6.0 \%)\end{array}$ & $<0.001 \dagger$ \\
\hline $\begin{array}{l}\text { 9-Month composite responders, } \\
\mathrm{n}(\%)\end{array}$ & $\begin{array}{l}n=60^{*} \\
37(61.7 \%)\end{array}$ & & $0.07 \S$ \\
\hline $\begin{array}{l}\text { 12-Month composite responders, } \\
\mathrm{n}(\%)\end{array}$ & $\begin{array}{l}n=61^{*} \\
40(65.6 \%)\end{array}$ & & $0.02 \S$ \\
\hline $\begin{array}{l}\text { Composite responder rates } \\
\text { ( } \geq 15 \text {-point } O D I \text { and } \geq 2 \mathrm{~cm} \\
\text { VAS reduction) }\end{array}$ & & $\begin{array}{l}\text { Basivertebral } \\
\text { nerve ablation } \\
\text { in the former } \\
\text { standard care } \\
\text { arm } \\
(n=61)\end{array}$ & \\
\hline $\begin{array}{l}\text { 3-Month composite responders, } \\
\text { n (\%) }\end{array}$ & & $\begin{array}{l}n=60^{*} \\
34(56.7 \%)\end{array}$ & $0.30 \S$ \\
\hline $\begin{array}{l}\text { 6-Month composite responders, } \\
\mathrm{n}(\%)\end{array}$ & & $\begin{array}{l}n=58^{*} \\
36(62.1 \%)\end{array}$ & $0.07 \S$ \\
\hline
\end{tabular}

Composite responder rates were defined as $\geq 15$-point reduction in Oswestry Disability Index (ODI) and $\geq 2 \mathrm{~cm}$ reduction in Visual Analog Scale (VAS). Significant differences were observed at 3 and 6 months between the arms.

*As observed, with no imputation for missing data.

†P value from Fisher's exact test.

¥Standard care control arm 6 months as last attended (median follow-up of 176.5

days).

$\S P$ value from a binomial test.

ODI, Oswestry Disability Index; VAS, Visual Analog Scale.

to positioning and length of the procedure, and one patient complained of incision site pain post procedure. There were 13 (10.2\%) non-serious device-procedure-related leg pain events in the $127 \mathrm{BVN}$ ablation procedures ( 66 treatment arm and $61 \mathrm{BVN}$ ablation in the former SC arm patients). Leg pain events were transient, with resolution in a median of 43 days, and primarily treated with oral medication. All leg pain events except one were associated with a pedicle breach. For the remaining leg pain event, potential access issues could not be evaluated due to technical limitations of the follow-up MRI. Other general procedurerelated events included one urinary retention, one nausea, one skin rash from prep solution, one corneal abrasion related to surgical eye protection and one incision infection. Finally, of the 127 patients treated with BVN ablation (66 treatment arm and 61 BVN ablation in the former SC arm patients), approximately half $(47 \%)$ received moderate conscious sedation. Only one of these patients could not tolerate the procedure under moderate conscious sedation and was converted to general anesthesia.

\section{DISCUSSION}

This report outlines the between-group results of the INTRACEPT trial for the full RCT cohort at the 3-month primary endpoint and at 6 months (or at the time of re-baseline prior to offering BVN ablation to the SC arm). It also includes the 12-month results for the BVN ablation arm and the 6-month outcomes after BVN ablation in the former SC arm. Statistically significant and clinically meaningful differences in favor of BVN ablation were observed in the RCT for the primary outcome and all secondary outcomes at the 3 -month primary endpoint and at 6 months. These results were durable at 12 months in the original BVN ablation arm; and comparable improvements in pain
Table 7 Basivertebral nerve ablation arm: 12-month pain and function improvements

\begin{tabular}{|c|c|c|}
\hline Oswestry Disability Index (ODI) & $\begin{array}{l}\text { Basivertebral nerve } \\
\text { ablation arm } \\
(\mathrm{N}=66)\end{array}$ & $P$ value \\
\hline \multicolumn{3}{|l|}{ Baseline ODI } \\
\hline Mean, SD (range) & $44.7,11.3(30-76)$ & \\
\hline 9-Month ODI & $n=60^{*}$ & \\
\hline Mean, SD (Rrange) & $18.8,16.4$ (0 to -64$)$ & \\
\hline Change from baseline, mean, SD & $-25.6,17.1$ & $<0.001 \dagger$ \\
\hline 12-Month ODI & $\mathrm{n}=61^{*}$ & \\
\hline Mean, SD (Rrange) & $18.6,15.7(0$ to -60$)$ & \\
\hline Change from baseline, mean, SD & $-25.7,18.5$ & $<0.001 \dagger$ \\
\hline 9-Month Rresponder Rrate & $n=60^{*}$ & \\
\hline 215-point ODI reduction, n (\%) & $40(66.7 \%)$ & $0.010 \ddagger$ \\
\hline$\geq 20$-point reduction from baseline, $n(\%)$ & $35(58.3 \%)$ & $0.197 \ddagger$ \\
\hline 12-Month Rresponder Rrate & $\mathrm{n}=61^{*}$ & \\
\hline$\geq 15$-point ODI reduction, $\mathrm{n}(\%)$ & $42(68.9 \%)$ & $0.003 \ddagger$ \\
\hline$\geq 20$-point reduction from baseline, $n(\%)$ & $37(60.7 \%)$ & $0.096 \ddagger$ \\
\hline Visual Analog Scale (VAS) & $\begin{array}{l}\text { Basivertebral nerve } \\
\text { ablation arm } \\
(\mathrm{n}=66)\end{array}$ & $P$ value \\
\hline \multicolumn{3}{|l|}{ Baseline VAS } \\
\hline Mean, SD (range) & $6.7,1.3(4-10)$ & \\
\hline 9-Month VAS & $\mathrm{n}=60^{*}$ & \\
\hline Mean, SD (Rrange) & $2.6,2.5$ (0 to -8$)$ & \\
\hline Change from baseline, mean, SD & $-4.0,2.6$ & $<0.001 \dagger$ \\
\hline 12-Month VAS & $\mathrm{n}=61$ * & \\
\hline Mean, SD (Rrange) & $2.9,2.6$ (0 to -8$)$ & \\
\hline Change from baseline, mean, SD & $-3.8,2.6$ & $<0.001 \dagger$ \\
\hline 9-Month Rresponder Rrate & $\mathrm{n}=60^{*}$ & \\
\hline$\geq 2 \mathrm{~cm}$ reduction, $\mathrm{n}(\%)$ & $45(75.0 \%)$ & $<0.001 \ddagger$ \\
\hline 12-Month Rresponder Rrate & $\mathrm{n}=61^{*}$ & \\
\hline$\geq 2 \mathrm{~cm}$ reduction, $\mathrm{n}(\%)$ & $48(78.7 \%)$ & $<0.001 \ddagger$ \\
\hline
\end{tabular}

Comparisons to baseline at 9 and 12 months for basivertebral nerve ablation arm patients were significant for both pain and function.

${ }^{*}$ As observed. No imputations for missing values.

tP value from a paired t-test (baseline to 9 and 12 months) for the BNV ablation arm.

$\ddagger P$ value from a binomial test.

ODI, Oswestry Disability Index; VAS, Visual Analog Scale.

and function were observed 6 months after BVN ablation in the former SC arm.

These findings demonstrate that BVN ablation is more effective than SC. BVN ablation was performed at 20 different sites by proceduralists from different specialties, suggesting generalizability of these outcomes to patients meeting the study's strict inclusion and exclusion criteria. These results also demonstrate reproducibility of treatment outcomes from a previous shamcontrolled trial of BVN ablation. ${ }^{8}$ In addition, patients maintained their improvements in pain and function through 12 months, highlighting the durability of this treatment. Likewise, long-term follow-up of the BVN ablation arm in the previous sham-controlled trial revealed durability of benefits at 2 years 
Percent Visual Analog Scale (VAS) Pain Score Reduction: Baseline to 12 Months in the Basivertebral Ablation Treatment Arm

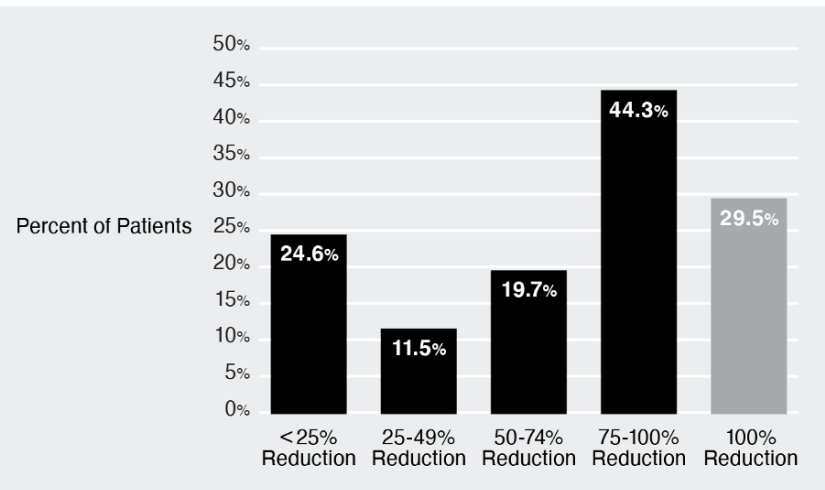

Figure 2 Visual Analog Scale (VAS) pain reduction by quadrant of improvement at 12 months in the basivertebral nerve (BVN) ablation arm. Sixty-four per cent of BVN ablation treatment arm patients reported a greater than $50 \%$ reduction in pain from baseline and $29.5 \%$ had complete pain relief.

\begin{tabular}{|c|c|c|}
\hline Quality of life measurements & $\begin{array}{l}\text { Basivertebral nerve } \\
\text { ablation } \operatorname{arm}(n=66)\end{array}$ & $P$ value \\
\hline \multicolumn{3}{|l|}{ Baseline SF-36 (PCS) } \\
\hline Mean, SD (Range) & \multicolumn{2}{|l|}{$32.1,6.8(18.4-46.9)$} \\
\hline 9 Month SF-36 (PCS) & \multicolumn{2}{|l|}{$n=60^{*}$} \\
\hline Mean, SD (Range) & \multicolumn{2}{|l|}{$46.8,9.5(25.8-60.8)$} \\
\hline Mean Change from Baseline, SD & $14.5,9.5$ & $<0.001 \dagger$ \\
\hline 12 Month SF-36 (PCS) & \multicolumn{2}{|l|}{$61^{*}$} \\
\hline Mean, SD (Range) & \multicolumn{2}{|l|}{$47.0,9.9(25.5-62.2)$} \\
\hline Mean Change from Baseline, SD & $14.9,10.2$ & $<0.001 \dagger$ \\
\hline \multicolumn{3}{|l|}{ Baseline SF-36 (MCS) } \\
\hline Mean, SD (Range) & \multicolumn{2}{|l|}{$53.4,9.5(22.2-69.8)$} \\
\hline 9 Month SF-36 (MCS) & \multicolumn{2}{|l|}{$\mathrm{n}=60^{*}$} \\
\hline Mean, SD (Range) & \multicolumn{2}{|l|}{$54.1,8.6(21.1-64.8)$} \\
\hline Mean Change from Baseline, SD & $0.7,7.5$ & $0.48^{b}$ \\
\hline 12 Month SF-36 (MCS) & \multicolumn{2}{|l|}{$\mathrm{n}=61^{*}$} \\
\hline Mean, SD (Range) & \multicolumn{2}{|l|}{$54.4,7.6(26.6-63.5)$} \\
\hline Mean Change from Baseline, SD & $0.8,8.0$ & $0.42 \dagger$ \\
\hline \multicolumn{3}{|l|}{ Baseline EQ-5D-5L } \\
\hline Mean, SD (Range) & \multicolumn{2}{|l|}{$0.61,0.13(0.27-0.83)$} \\
\hline 9 Month EQ-5D-5L & \multicolumn{2}{|l|}{$\mathrm{n}=60^{*}$} \\
\hline Mean, SD (Range) & \multicolumn{2}{|l|}{$0.81,0.16(0.42-1.00)$} \\
\hline Mean Change from Baseline, SD & $0.19,0.18$ & $<0.001 \dagger$ \\
\hline 12 Month EQ-5D-5L & \multicolumn{2}{|l|}{$\mathrm{n}=61^{*}$} \\
\hline Mean, SD (Range) & \multicolumn{2}{|l|}{$0.81,0.16(0.35-1.00)$} \\
\hline Mean Change from Baseline, SD & $0.19,0.19$ & $<0.001 \dagger$ \\
\hline \multicolumn{3}{|c|}{$\begin{array}{l}\text { Significant differences were observed for the Physical Component Summary but not } \\
\text { the Mental Component Summary in the basivertebral nerve ablation treatment arm } \\
\text { at } 9 \text { and } 12 \text { months post procedure compared with baseline. } \\
\text { *As observed. No imputations for missing values. } \\
\text { tP value from a paired t-test (baseline to } 9 \text { and } 12 \text { months) for the BNV ablation } \\
\text { arm. } \\
\text { EQ-5D-5L, EuroQual Group } 5 \text { Dimension 5-Level Quality of Life; MCS, Mental } \\
\text { Component Summary; PCS, Physical Component Summary; QOL, quality of life; SF, } \\
\text { Short Form. }\end{array}$} \\
\hline
\end{tabular}

Table 9 Basivertebral nerve ablation in the former standard care arm: 6-month function and pain improvement results

\begin{tabular}{|c|c|c|}
\hline Oswestry Disability Index (ODI) & $\begin{array}{l}\text { Basivertebral nerve ablation } \\
\text { in the former standard care } \\
\operatorname{arm}(n=61)\end{array}$ & $P$ value \\
\hline \multicolumn{3}{|l|}{ Re-baseline ODI } \\
\hline Mean, SD (Range) & $46.2,11.7$ (26 to 76$)$ & \\
\hline 3 Month ODI & $n=60^{*}$ & \\
\hline Mean, SD (Range) & $21.5,16.2$ (0 to 66$)$ & \\
\hline Change from baseline Mean, SD & $-24.7,18.5$ & $<0.001 \dagger$ \\
\hline 6 Month ODI & $\mathrm{n}=58^{*}$ & \\
\hline Mean, SD (Range) & $20.4,16.8$ (0 to 62$)$ & \\
\hline \multicolumn{3}{|l|}{ Change from baseline } \\
\hline Mean, SD & $-25.9,17.1$ & $<0.001 \dagger$ \\
\hline 3 Month Responder Rate & $\mathrm{n}=60^{*}$ & \\
\hline$\geq 15$-point ODI reduction $\mathrm{n}(\%)$ & $38(63.3 \%)$ & $0.04 \ddagger$ \\
\hline $\begin{array}{l}\geq 20 \text {-point reduction from baseline } \\
\mathrm{n}(\%)\end{array}$ & $33(55.0 \%)$ & $0.44 \ddagger$ \\
\hline 6 Month Responder Rate & $n=58^{*}$ & \\
\hline$\geq 15$-point ODI reduction $n(\%)$ & $42(72.4 \%)$ & $<0.001 \ddagger$ \\
\hline $\begin{array}{l}\geq 20 \text {-point reduction from baseline } \\
\mathrm{n}(\%)\end{array}$ & $35(60.3 \%)$ & $0.12 \ddagger$ \\
\hline Visual Analog Scale (VAS) & $\begin{array}{l}\text { Basivertebral nerve ablation } \\
\text { in the former standard care } \\
\operatorname{arm}(n=61)\end{array}$ & P Value \\
\hline \multicolumn{3}{|l|}{ Re-baseline VAS } \\
\hline Mean, SD (Range) & $6.8,1.3$ (3 to 10$)$ & \\
\hline 3 Month VAS & $\mathrm{n}=60^{*}$ & \\
\hline Mean, SD (Range) & $3.3,2.5$ (0 to 8$)$ & \\
\hline Change from baseline Mean, SD & $-3.5,2.6$ & $<0.001 \dagger$ \\
\hline 6 Month VAS & $n=58^{*}$ & \\
\hline Mean, SD (Range) & $2.9,2.6$ (0 to 8$)$ & \\
\hline \multicolumn{3}{|l|}{ Change from baseline } \\
\hline Mean, SD & $-3.8,2.9$ & $<0.001 \dagger$ \\
\hline 3 Month Responder Rate & $\mathrm{n}=60^{*}$ & \\
\hline$\geq 2 \mathrm{~cm}$ reduction $\mathrm{n}(\%)$ & $47(78.3 \%)$ & $<0.001 \ddagger$ \\
\hline 6 Month Responder Rate & $\mathrm{n}=58^{*}$ & \\
\hline$\geq 2 \mathrm{~cm}$ reduction $\mathrm{n}(\%)$ & $43(74.1 \%)$ & $<0.001 \ddagger$ \\
\hline
\end{tabular}

At 3 and 6 months following basivertebral nerve ablation, reductions from rebaseline were significant for both pain and function in former standard care arm patients.

${ }^{*}$ As observed. No imputations for missing values.

tP value from a paired t-test (baseline to 9 and 12 months) for the BNV ablation arm.

$\ddagger P$ value from a Binomial test.

ODI, Oswestry Disability Index; VAS, Visual Analog Scale.

$(\mathrm{ODI}-23.4 \text { and VAS }-3.59)^{9}$ and at 5 years (ODI -25.95 and VAS -4.38$)^{10}$

Commonly available treatments aimed at CLBP are often limited by low effect sizes ${ }^{1}$ and can leave patients dissatisfied. ${ }^{18}$ One drawback of an unblinded RCT with an SC control arm, such as this study, is the potential for a nocebo effect in the SC group. ${ }^{19}$ Yet, the SC arm results from this study (mean -4.0 points change in ODI at the 3-month primary endpoint) are in line with those from prior published CLBP studies. For example, similarly low effect sizes have been reported for CLBP treatment with yoga (ODI difference of 7.4) ${ }^{20}$ massage (Roland-Morris Disability Questionnaire (RDQ) difference of 2.9), ${ }^{21}$ acupuncture (RDQ difference of 1.9 ), ${ }^{22}$ multidisciplinary rehabilitation (RDQ difference of 1.5), ${ }^{23}$ Pilates (RDQ difference 1.4), ${ }^{24}$ and non-steroidal anti-inflammatory drugs (NSAIDs) (RDQ 0.85). ${ }^{2.5}$ 
Percent Visual Analogue Scale (VAS) Pain Score

Reduction: Re-baseline to 6 Months Post Basivertebral Nerve Ablation in the Former Standard Care Arm

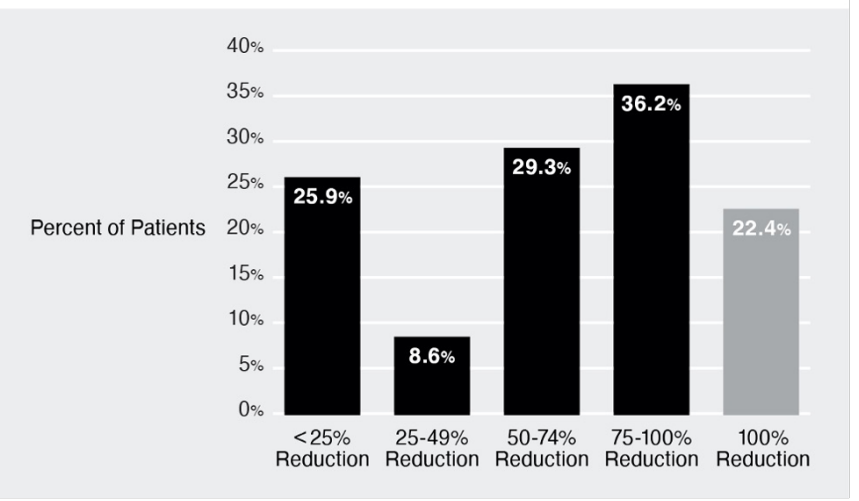

Figure 3 Visual Analog Scale (VAS) pain reduction by quadrant of improvement at 6 months after basivertebral nerve (BVN) ablation in the former standard care arm. More than $65 \%$ of these patients reported a greater than $50 \%$ reduction in pain from re-baseline and $22.4 \%$ reported complete pain relief.

In addition, several CLBP treatments have failed to demonstrate significant improvements in function relative to SC, including spinal manipulative therapy, ${ }^{26}$ cognitive-behavioral therapy, ${ }^{27}$ and mindfulness-based therapy. ${ }^{28}$

Changing focus to invasive treatment of CLBP, a meta-analysis comparing segmental spinal fusion to non-operative SC for CLBP demonstrated a mean ODI difference of 5.13 points in favor of fusion with similar SC results as our study. ${ }^{29}$ In contrast, our study revealed a 25.7-point difference in mean ODI in favor of BVN ablation. Another well-studied radiofrequency nerve ablation treatment for CLBP, medial branch radiofrequency ablation, demonstrated comparable effectiveness to our study in wellselected patients (RDQ difference of 5, VAS difference of 3.2,

Mean Oswestry Disability Index (ODI) Over Time

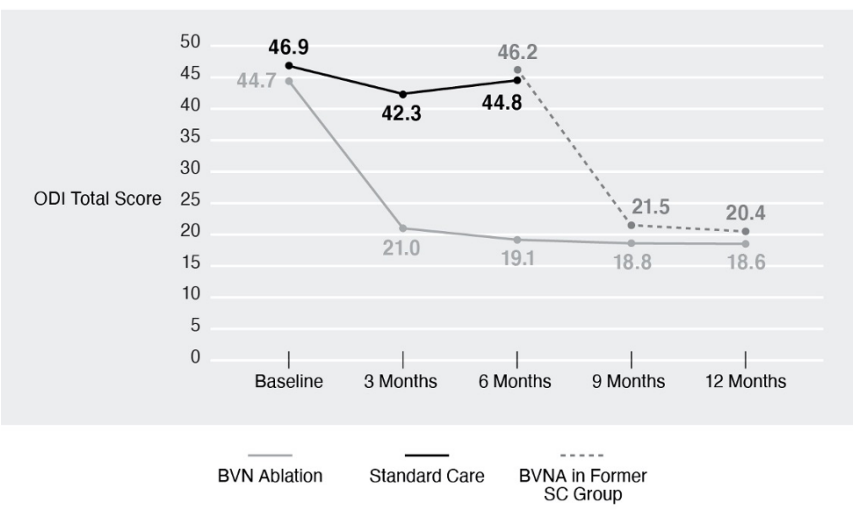

Figure 4 Mean ODI over time. A statistically significant and clinically meaningful difference in ODI was observed, demonstrating superiority of BVN ablation over standard care. Comparable ODI reduction was demonstrated following BVN ablation in the former SC arm patients at 3 and 6 months post procedure. BVN, basivertebral nerve; BVNA, basivertebral nerve ablation; ODI, Oswestry Disability Index; SC, standard care.
Mean Visual Analogue Scale (VAS) Pain Score Over Time

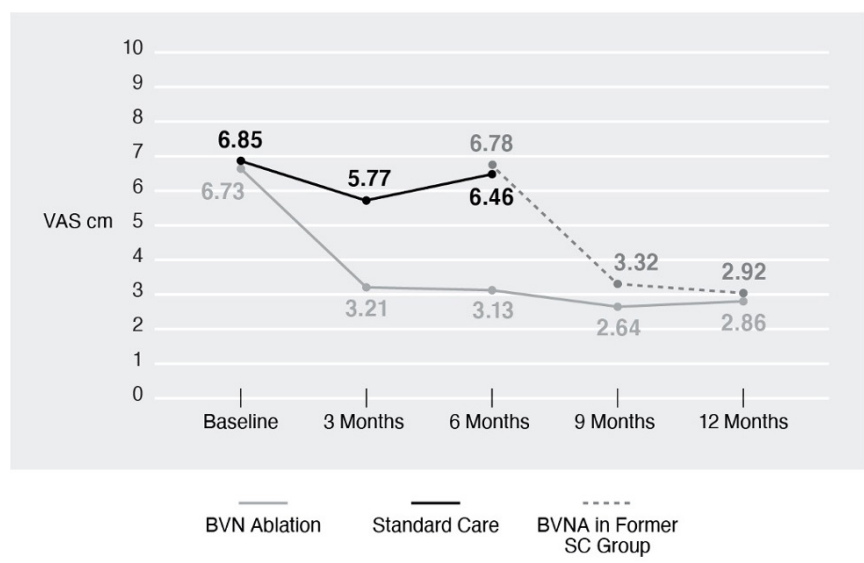

Figure 5 Mean VAS over time. A statistically significant and clinically meaningful difference in VAS was observed, demonstrating superiority of BVN ablation over standard care. Comparable VAS reduction was demonstrated following BVNA in the former SC arm at 3 and 6 months post procedure. BVN, basivertebral nerve; BVNA, basivertebral nerve ablation; SC, standard care; VAS, Visual Analog Scale.

with $60 \%$ of patients achieving $80 \%$ pain relief). ${ }^{30}$ However, this example further demonstrates that careful subgrouping is necessary for optimal results, as these good outcomes are only observed in patients selected by stringent criteria for diagnostic medial branch blocks and treated with anatomically accurate nerve ablation technique. ${ }^{31}$

\section{Strengths and weaknesses}

One strength of this study is the robust statistical superiority of BVN ablation over SC in the primary outcome and all secondary outcomes at both timepoints of the RCT. Statistical superiority was also demonstrated at the preplanned interim analysis which led to the DMC's recommendation to halt enrollment and offer SC patients BVN ablation earlier than specified in original the protocol. ${ }^{11}$ While enrollment and randomization was halted because the study had accomplished its stated purpose to demonstrate a significant difference in the primary outcome at the primary endpoint, the study continued to follow the BVN ablation arm patients and all SC arm patients who elected to receive BVN ablation. Accordingly, this did limit the RCT comparison of outcomes beyond 6 months.

Despite robust improvements in pain, no significant differences in opioid use were observed at 6-month follow-up. While surprising on the surface, this is a common finding in studies of populations with chronic pain. Many effective chronic pain interventions, such as spinal cord stimulation, fail to demonstrate reduction in opioid use. ${ }^{32}$ This disconnect between pain reduction and opioid use highlights the known complexity of factors driving opioid use, beyond changes in pain. Accordingly, longer-term follow-up may be needed to observe changes in opioid behaviors as demonstrated by a secondary analysis of data from the previous sham-controlled RCT of BVN ablation that showed opioid reduction in the subgroup reporting improvements in pain during long-term follow-up. ${ }^{33}$

Other important strengths of this study include the randomized, controlled design, with direct comparison to SC through 6 months. Additionally, this study demonstrates reproducibility 
Table 10 Basivertebral nerve ablation in the former standard care arm: 6-month quality of life results

\begin{tabular}{|c|c|c|}
\hline Quality of life measurements & $\begin{array}{l}\text { Basivertebral nerve } \\
\text { ablation in the } \\
\text { former standard care } \\
\operatorname{arm}(n=61)\end{array}$ & P-Value \\
\hline \multicolumn{3}{|l|}{ Baseline SF-36 (PCS) } \\
\hline Mean, SD (Range) & $33.1,5.6(20.9-45.2)$ & \\
\hline 3 Month SF-36 (PCS) & $\mathrm{n}=60^{*}$ & \\
\hline Mean, SD (Range) & $44.9,9.1(23.1-59.7)$ & \\
\hline Mean Change from Baseline, SD & $11.8,8.4$ & $<0.001 \dagger$ \\
\hline 6 Month SF-36 (PCS) & $\mathrm{n}=58^{*}$ & \\
\hline Mean, SD (Range) & $45.8,10.2(22.3-59.3)$ & \\
\hline Mean Change from Baseline, SD & $12.6,9.6$ & $<0.001 \dagger$ \\
\hline \multicolumn{3}{|l|}{ Baseline SF-36 (MCS) } \\
\hline Mean, SD (Range) & $49.2,11.6(21.6-66.3)$ & \\
\hline 3 Month SF-36 (MCS) & $\mathrm{n}=60^{*}$ & \\
\hline Mean, SD (Range) & $54.5,8.5(23.5-66.1)$ & \\
\hline Mean Change from Baseline, SD & $5.1,11.1$ & $<0.001 \dagger$ \\
\hline 6 Month SF-36 (MCS) & $n=58^{*}$ & \\
\hline Mean, SD (Range) & $54.3,8.5(23.9-63.6)$ & \\
\hline Mean Change from Baseline, SD & $5.1,11.1$ & $<0.001 \dagger$ \\
\hline \multicolumn{3}{|l|}{ Baseline EQ-5D-5L } \\
\hline Mean, SD (Range) & $0.61,0.13(0.28-0.86)$ & \\
\hline 3 Month EQ-5D-5L & $\mathrm{n}=60^{*}$ & \\
\hline Mean, SD (Range) & $0.79,0.14(0.43-1.00)$ & \\
\hline Mean Change from Baseline, SD & $0.18,0.17$ & $<0.001 \dagger$ \\
\hline 6 Month EQ-5D-5L & $\mathrm{n}=58^{*}$ & \\
\hline Mean, SD (Range) & $0.80,0.14(0.48-1.00)$ & \\
\hline Mean Change from Baseline, SD & $0.20,0.18$ & $<0.001 \dagger$ \\
\hline
\end{tabular}

Significant differences were observed at 3 and 6 months post basivertebral nerve ablation compared with re-baseline.

${ }^{*}$ As observed. No imputations for missing values.

tP value from a paired t-test (baseline to 3 and 6 months) for the standard care with BNV ablation group.

EQ-5D-5L, EuroQual Group 5 Dimension 5-Level Quality of Life; MCS, Mental Component Summary; PCS, Physical Component Summary; QOL, quality of life; SF, Short Form.

with results comparable to a separate prior RCT, and generalizability to North American clinics having involved 20 separate clinical sites and many different specialists performing BVN ablation. Additional limitations include the potential sources of bias, such as the non-structured SC control, the open label design, and industry funding. Another important limitation of this study is a lack of generalizability to the broader CLBP population given the strict clinical and radiographic criteria.

\section{CONCLUSIONS}

This study demonstrates the clinical effectiveness of BVN ablation with direct comparison to SC. Patients treated with BVN ablation exhibited statistically significant and clinically meaningful improvements in ODI, VAS, SF-36, and EQ-5D-5L compared with SC controls at 3 and 6 months, with durability of the treatment response at 12 months. Similar results were observed 6 months after BVN ablation in the former SC arm, further demonstrating effectiveness and reproducibility. This is not a treatment for all CLBP as these results are limited to a subset of patients with vertebrogenic CLBP who meet the study's strict clinical and radiographic criteria.
Collaborators INTRACEPT Trial Investigators: Douglas Beall, MD, Clinical Investigations, LLC; Scott Bainbridge, MD, Denver Back Pain Specialists; Jad Khalil, MD, William Beaumont Hospital; Theodore Koreckij, MD, Saint Luke's Hospital; Paul Kalapos, MD, Penn State Hershey Medical Center; Frank Phillips, MD, Rush University Medical Center; John Keel, MD, Emory University; Jeffrey Wang, MD, Keck Hospital of USC; Matthew Smuck, MD, Stanford Hospital; Charles Munyon, MD, Temple University; John Markman, MD, University of Rochester; Bruce Vrooman, MD, Dartmouth Hitchock Medical Center; Neel Anand, MD, Cedars Sinai Spine Center; Daniel Lieberman, MD, Phoenix Spine; Larry Shannon II, MD, Bassett Medical Center; Scott Kreiner, MD, Barrow Brain and Spine; Aaron Calodney, MD, Precision Spine Care; Ken Yonemura, MD, Salt Lake Center for Spine and Peripheral Nerve Surgery; Bradly Goodman, MD, Alabama Clinical Therapeutics, LLC; Gregory Moore, MD, NeuroSpine Institute; Michael Schaufele, MD, Drug Studies America; Al Rhyne, MD, OrthoCarolina; Dan Nguyen, MD, Oklahoma Spine Hospital.

Contributors All authors has a substantial contributions to the conception or design of the work, acquisition, analysis and interpretation of data including drafting the work and revising it critically for important intellectual content. All authors provided final approval of the version published.

Funding This study was funded by Relievant Medsystems.

Competing interests The following authors declare conflicts of interest related to consulting, teaching/proctoring roles, and/or scientific board roles for Relievant Medsystems: Dr SG, Dr JH, Dr JK and Dr NM. The following authors declare conflicts of interest for research funding paid to their institution from Relievant Medsystem during the conduct of the study: Dr JK, Dr SK, Dr TK, and Dr MS. The following authors declare no conflicts of interest for the submitted work: Dr KB.

\section{Patient consent for publication Obtained.}

Provenance and peer review Not commissioned; externally peer reviewed.

Data availability statement Data are available on reasonable request. Requests for study protocol and deidentified data access should be forwarded to VP Clinical Affairs, Relievant Medsystems at dsahr@relievant.com.

Open access This is an open access article distributed in accordance with the Creative Commons Attribution Non Commercial (CC BY-NC 4.0) license, which permits others to distribute, remix, adapt, build upon this work non-commercially, and license their derivative works on different terms, provided the original work is properly cited, an indication of whether changes were made, and the use is noncommercial. See: http://creativecommons.org/licenses/by-nc/4.0/.

\section{REFERENCES}

1 Keller A, Hayden J, Bombardier C, et al. Effect sizes of non-surgical treatments of nonspecific low-back pain. Eur Spine J 2007;16:1776-88

2 Lotz JC, Fields AJ, Liebenberg EC. The role of the vertebral end plate in low back pain. Global Spine J 2013;3:153-63.

3 Fras C, Kravetz P, Mody DR, et al. Substance P-containing nerves within the human vertebral body. An immunohistochemical study of the basivertebral nerve. Spine J 2003:3:63-7.

4 Dudli S, Fields AJ, Samartzis D, et al. Pathobiology of Modic changes. Eur Spine J 2016;25:3723-34.

5 Fagan A, Moore R, Vernon Roberts B, et al. ISSLS Prize winner: the innervation of the intervertebral disc: a quantitative analysis. Spine 2003;28:2570-6.

6 Kjaer P, Korsholm L, Bendix T, et al. Modic changes and their associations with clinical findings. Eur Spine J 2006;15:1312-9

7 Braithwaite I, White J, Saifuddin A, et al. Vertebral end-plate (Modic) changes on lumbar spine MRI: correlation with pain reproduction at lumbar discography. Eur Spine J 1998;7:363-8.

8 Fischgrund JS, Rhyne A, Franke J, et al. Intraosseous basivertebral nerve ablation for the treatment of chronic low back pain: a prospective randomized double-blind shamcontrolled multi-center study. Eur Spine J 2018;27:1146-56.

9 Fischgrund JS, Rhyne A, Franke J, et al. Intraosseous basivertebral nerve ablation for the treatment of chronic low back pain: 2 -year results from a prospective randomized double-blind sham-controlled multicenter study. Int J Spine Surg 2019;13:110-9.

10 Fischgrund IS, Rhyne A, Macadaeg K, et al. Long-Term outcomes following Intraosseous basivertebral nerve ablation for the treatment of chronic low back pain: 5-year treatment arm results from a prospective randomized double-blind shamcontrolled multi-center study. Eur Spine J 2020;29:1925-34.

11 Khalil JG, Smuck M, Koreckij T, et al. A prospective, randomized, multicenter study of Intraosseous basivertebral nerve ablation for the treatment of chronic low back pain. Spine J 2019;19:1620-32

12 Roland M, Fairbank J. The Roland-Morris disability questionnaire and the Oswestry disability questionnaire. Spine 2000:25:3115-24.

13 Copay AG, Glassman SD, Subach BR, et al. Minimum clinically important difference in lumbar spine surgery patients: a choice of methods using the Oswestry disability index, medical outcomes study questionnaire short form 36 , and pain scales. Spine $J$ 2008;8:968-74. 
14 Price DD, McGrath PA, Rafii A, et al. The validation of visual analogue scales as ratio scale measures for chronic and experimental pain. Pain 1983;17:45-56.

15 Brazier JE, Harper R, Jones NM, et al. Validating the SF-36 health survey questionnaire: new outcome measure for primary care. BMJ 1992;305:160-4.

16 Herdman M, Gudex C, Lloyd A, et al. Development and preliminary testing of the new five-level version of EQ-5D (EQ-5D-5L). Qual Life Res 2011:20:1727-36.

17 Jamison RN, Raymond SA, Slawsby EA, et al. Pain assessment in patients with low back pain: comparison of Weekly recall and momentary electronic data. J Pain 2006;7:192-9.

18 Silvis WL, Lakke SE, Stegeman P, et al. Can patients with low back pain be satisfied with less than expected? Spine 2016:41:1606-12.

19 Colloca L, Barsky AJ. Placebo and nocebo effects. New England Journal of Medicine 2020:382:554-61.

20 Williams K, Abildso C, Steinberg L, et al. Evaluation of the effectiveness and efficacy of lyengar yoga therapy on chronic low back pain. Spine 2009;34:2066-76.

21 Cherkin DC, Sherman KJ, Kahn J, et al. A comparison of the effects of 2 types of massage and usual care on chronic low back pain: a randomized, controlled trial. Ann Intern Med 2011:155:1-9.

22 Cherkin DC, Sherman KJ, Avins AL, et al. A randomized trial comparing acupuncture, simulated acupuncture, and usual care for chronic low back pain. Arch Intern Med 2009;169:858-66.

23 Kamper SJ, Apeldoorn AT, Chiarotto A, et al. Multidisciplinary biopsychosocial rehabilitation for chronic low back pain: cochrane systematic review and metaanalysis. BMJ 2015;350:h444
24 Miyamoto GC, Costa LOP, Galvanin T, et al. Efficacy of the addition of modified Pilates exercises to a minimal intervention in patients with chronic low back pain: a randomized controlled trial. Phys Ther 2013;93:310-20.

25 Enthoven WTM, Roelofs PD, Koes BW. Nsaids for chronic low back pain. JAMA 2017;317:2327-8

26 Assendelft WJJ, Morton SC, Yu El, et al. Spinal manipulative therapy for low back pain. A meta-analysis of effectiveness relative to other therapies. Ann Intern Med 2003; 138:871-81.

27 Henschke N, Ostelo RW, van Tulder MW, et al. Behavioural treatment for chronic lowback pain. Cochrane Database Syst Rev 2010:CD002014.

28 Cherkin DC, Anderson ML, Sherman KJ, et al. Two-Year follow-up of a randomized clinical trial of mindfulness-based stress reduction vs cognitive behavioral therapy or usual care for chronic low back pain. JAMA 2017;317:642-4.

29 Yavin D, Casha S, Wiebe S, et al. Lumbar fusion for degenerative disease: a systematic review and meta-analysis. Neurosurgery 2017:80:701-15.

30 Dreyfuss $\mathrm{P}$, Halbrook B, Pauza K, et al. Efficacy and validity of radiofrequency neurotomy for chronic lumbar zygapophysial joint pain. Spine 2000:25:1270-7.

31 McCormick ZL, Vorobeychik Y, Gill JS, et al. Guidelines for composing and assessing a paper on the treatment of pain: a practical application of evidence-based medicine principles to the MINT randomized clinical trials. Pain Med 2018;19:2127-37.

32 Hwang BY, Negoita S, Duy PQ, et al. Opioid use and spinal cord stimulation therapy: the long game. J Clin Neurosci 2021;84:50-2.

33 Markman JD, Rhyne AL, Sasso RC, et al. Association between opioid use and patientreported outcomes in a randomized trial evaluating Basivertebral nerve ablation for the relief of chronic low back pain. Neurosurgery 2020;86:343-7. 